\title{
Pembelajaran Awal Praktek Instrumen Biola di Prodi Pendidikan Musik Jurusan Sendratasik Fakultas Bahasa dan Seni Universitas Negeri Padang
}

\author{
Yensharti $^{1}$, Delvia Mona ${ }^{2}$ \\ Jurusan Sendratasik, Fakultas Bahasa dan Seni, \\ Universitas Negeri Padang, Alamat Jl. Prof. Dr. Hamka, \\ Air Tawar, Kota Padang Sumbar 25171, Indonesia \\ Email: yensharti@fbs.unp.ac.id
}

\begin{abstract}
Abstrak
Penelitian ini bertujuan untuk mendeskripsikan pembelajaran awal praktek instrumen biola pada mata kuliah Praktek Instrumen Mayor I di Prodi Pendidikan Musik Jurusan Sendratasik Fakultas Bahasa dan Seni Universitas Negeri Padang. Jenis penelitian adalah deskriptif kualitatif pendekatan studi pustaka, dan dokumentasi. Penelitian ini menggambarkan kegiatan pembelajaran biola meliputi pengenalan instrumen, pengenalan penggesek, pengenalan senar biola persiapan peserta didik dalam mempelajari biola terkait sikap atau posisi tubuh dalam memainkan instrumen biola, penggunaan penggesek memainkan nada dalam posisi open string, penggunaan penjarian dengan teknik gesekan Whole bow, Legato dan Staccato. Hasil penelitian menjelaskan posisi tubuh dan penggunaan bowing Whole Bow (W.B) dengan penjarian dan posisi yang tepat berguna untuk menguatkan teknik dasar dalam bermain biola yang bertujuan memantapkan bunyi nada yang berkualitas sesuai dengan teknik yang tepat untuk mendapatkan hasil belajar yang maksimal.
\end{abstract}

Kata Kunci: Pembelajaran Awal, Praktek Instrumen, Biola, Pendidikan Musik.

\begin{abstract}
This study aims to describe the practical learning of the violin instrument in the Mayor I Instrument Practice course at the Music Education Study Program, Department of Drama, Faculty of Language and Arts, Padang State University. This type of research is a literature study approach, and documentation. This study describes the violin learning activities including the introduction of the instrument, the introduction of the strings, the introduction of the violin strings, the preparation of students in studying the violin, attitudes or positions in playing the violin instrument, the use of friction in the open string position, the use of fingering with friction techniques related to Whole bow, Legato and Staccato. The results of the study explain the body position and the use of the Whole Bow (W.B) with proper fingering and positioning is useful for strengthening basic techniques in playing the violin which aims to strengthen the sound of quality notes according to the right technique to get maximum learning results
\end{abstract}

Keywords: Early Learning, Instrument Practice, Violin, Music Education. 


\section{PENDAHULUAN}

Pembelajaran adalah suatu kegiatan terencana yang disiapkan oleh pendidik untuk anak didiknya. Dalam kegiatan tersebut terjadi interaksi antara pendidik dengan anak didik melalui komunikasi yang diciptakan menyangkut tujuan pembelajaran, materi yang harus dipahami peserta didik, media yang digunakan serta strategi dan metode yang dipakai pendidik sebagai prosedural untuk membawa peserta didik mencapai hasil belajar yang terstruktur dengan hasil yang maksimal.

Pendidik sebagai SDM utama menjadi motor penggerak agar peserta didik bisa bertindak dan berprilaku seperti alur yang diharapkan melalui tujuan pembelajaran yang telah dirancang. Peserta didik sebagai subyek penting yang akan menerima semua informasi yang diberikan pendidik dengan bersikap reaktif agar dapat menciptakan pembelajaran yang bermakna. Pengalaman belajar yang baik didapat dari keseriusan peserta didik untuk mengetahui lebih dalam tentang materi yang dipelajarinya. Tidak sekedar mengharapkan informasi dari pendidik saja tetapi juga berusaha mencari informasi dari berbagai sumber yang akhirnya dapat memperkaya pengetahuannya terkait materi yang dipelajari.

Pembelajaran musik menuntut peserta didik berprilaku lebih reaktif. Pembelajaran musik menuntut praktek musik dengan memahami bunyi secara logika dan rasa. Teori musik merupakan jalan untuk mengantarkan pada praktek bermain musik yang dilakukan secara rutin dan terarah dengan prosedur tertentu untuk mendapatkan hasil belajar yang maksimal.

Biola adalah salah satu instrumen musik yang dipelajari di Prodi Pendidikan Musik Jurusan Sendratasik. Mempelajari instrumen ini terdapat dalam mata kuliah Praktek Instrumen Mayor. Mata kuliah Praktek Instrumen Mayor dipelajari mahasiswa selama 4 semester dengan bobot 2 SKS dimulai dari semester 2. Tujuan penguasaan instrumen ini dipersiapkan untuk mendukung mata kuliah lainnya seperti mata kuliah ansambel dan komposisi musik. Materi perkuliahan yang diberikan berkaitan dengan permainan tangganada dan arpeggio serta latihan-latihan musikal berupa etude dan penguasaan lagu yang bersifat klasik dan populer. Hasil akhir perkuliahan diharapkan mahasiswa mampu menampilkan permainannya secara individual.

Ada beberapa teknik dasar dalam pembelajaran awal biola yang harus dikuasai dengan baik dan sungguh oleh mahasiswa, diantaranya adalah cara menempatkan instrumen (holding instrumen), cara memegang penggesek (bowing), cara menggesek senar pada posisi senar lepas (open string), menggunakan penjarian (fingering) 123 dan 4, menggunakan teknik gesekan Whole Bow (W.B), Legato dan Staccato. Keenam cara atau teknik ini menjadi dasar kuat untuk menghasilkan kualitas bunyi nada yang baik dan indah didengar pada awal pembelajaran instrumen ini.

Beberapa kendala ditemui setelah mengamati hasil pembelajaran pada semester sebelumnya, diantaranya masih terdapat mahasiswa yang belum memahami konsep bermain biola dengan baik dengan teknik yang benar. Kenyataan terlihat pada saat mengekspresikan lagu yang seharusnya menjadi bisa enak didengar dimainkan kurang indah bunyi nadanya, kualitas gesekan belum sempurna ada nada yang masih kurang tepat bunyinya atau fales-fales, begitu juga penggunakan bow (penggesek) yang tidak beraturan sehingga mahasiswa terkesan memainkan instrumen asal-asalan dan tidak sungguh-sungguh. Diduga hal ini terjadi karena kurang tepatnya menguasai dan memahami teknik permainan yang benar. Menyikapi kondisi tersebut perlu kiranya mahasiswa mengetahui teknik permainan biola secara tepat.

Tujuan penguasaan teknik ini merupakan dasar atau tonggak untuk mengokohkan permainan biola pada tahap berikutnya. Untuk mengedepankan aspek teknik pada awalnya dan mempunyai tahapan-tahapan yang mudah untuk dipelajari oleh pelajar pemula. Menyikapi permasalahan yang terjadi, penulis ingin menjelaskan secara terstruktur langkah-langkah teknik permainan biola awal yang dapat diikuti dengan sungguh-sungguh oleh mahasiswa agar dapat menghasilkan permainan biola dengan kualitas teknik permainan bunyi, nada yang indah dan enak didengar. 
Belajar merupakan kebutuhan dasar manusia untuk merubah prilakunya dari yang tidak tahu menjadi tahu, dari yang tidak mau menjadi mau dan dari yang tidak bisa menjadi bisa. Dalam belajar harus ada perubahan, konsep belajar seperti ini dikemukan oleh Slameto (2013) bahwa belajar pada hakekatnya adalah suatu proses usaha yang dilakukan seorang untuk memperoleh perubahan tinkah laku yang baru secara keseluruhan, sebagai hasil pengalamannya sendiri dalam interaksinya dengan lingkugan. Selanjutnya Sudjana (2013) dalam Baharun (2015) menyatakan hal yang sama bahwa belajar adalah suatu proses yang ditandai dengan adanya perubahan pada diri seseorang dimana perubahan itu dapat ditunjukkan dalam berbagai bentuk seperti penambahan pengetahuan, pemahaman, sikap dan tingkah laku, kecakapan, kebiaasaan serta perubahan aspekaspek lain yang ada pada individu-individu yang belajar. Pembelajaran bermakna (meaningfull learning) didapat jika peserta didik aktif mencari dan menemukan informasi yang berguna untuk dirinya.

Biola termasuk jenis instrumen yang bunyinya berasal dari dawai (senar). Menurut sejarah biola pertama kali diperkenalkan di Itali tepatnya di kota Turin pada tahun 1523. Pada mulanya senar biola berjumlah 3 namun sejak tahun 1540 berubah menjadi 4 senar dengan bentuk yang tidak terlalu berbeda dengan biola zaman sekarang. Biola termasuk alat musik chardophone yang bersumber bunyinya berasal dari dawai (Banoe, 2003). Biola merupakan salah satu dari kelompok instrumen gesek yang disebut violin. Panjang biola normal berukuran $4 / 4$ mencapai $60 \mathrm{~cm}$. Walaupun demikian ada juga yang lebih kecil yaitu berukuran $3 / 4$ dan $1 / 2$ dan $1 / 8$. Senar biola ada empat, senar yang paling rendah adalah nada $g$ atau disebut juga dengan senar 4 , disebelah senar $\mathrm{g}$ adalah senar d disebut juga dengan senar 3, dan disebelah senar d adalah senar a disebut juga senar 2 dan terakhir disebelah senar a adalah senar e disebut juga dengan senar 1. Batang tubuh biola memiliki dua bagian utama yakni, body biola dan penggesek (bow). Bagian tubuh secara detail meliputi, Table Belly, Ribs, Neck, Peg box, Scroll, Tail, Brige, Fingerboard, Lobang suara. busur penggesek (bow) biola terdiri dari tongkat kurang lebih panjang $75 \mathrm{~cm}$ dengan bulu-bulu kuda yang direntangkan di antara ujung tongkat penggesek.

\section{METODE PENELITIAN}

Metode penelitian ini menggunakan metode penelitian kualitatif. Menurut Sugiyono (2011) metode penelitian yang digunakan untuk meneliti pada kondisi objek secara alamiah dimana peneliti adalah instrument kunci. Sedangkan menurut Saryono (2013:1). Penelitian kualitatif merupakan penelitian yang digunakan untuk menyelidiki, menemukan, menggambarkan, dan menjelaskan kualitas atau keistimewaan dari pengaruh social yang tidak dapat dijelaskan, diukur atau digambarkan melalui pendekatan kuantitatif. Pada penulisan ini penulis menggunakan metode kualitatif deskriptif dengan pendekatan studi pustaka, dan dokumentasi.

\section{HASIL DAN PEMBAHASAN \\ Mengenal Instrumen Biola dan Bagian-bagiannya}

Pembelajaran awal dimulai dengan pengenalan terhadap instrumen biola. Ada dua bagian utama biola yang masing-masing memiliki kegunaan dan fungsi yang berbeda. Bagian tersebut adalah tubuh biola dan penggesek biola (bowing). 


\section{a. Tubuh Biola}

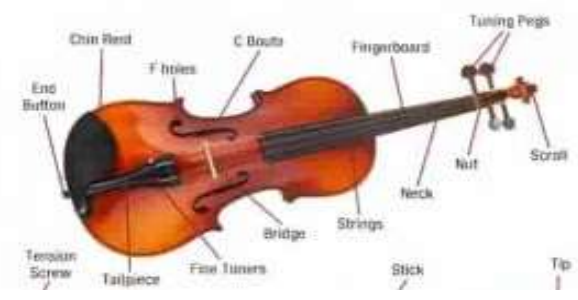

Gambar 1. Tubuh Biola

Tubuh biola terdiri 11 bagian yakni : scrool, pegbox, neck, fingerboard, upper boat, waist, F-holes, bridge, fine tumers, tailpiece dan chinrest. Scroll merupakan bagian kepala biola yang bentuknya seperti gulungan. Pegbox adalah kayu pemutar yang gunanya untuk meletakkan senar biola serta menyetemnya sesuai denga ketinggian tertentu. Neck adalah bagian leher biola yang gunanya untuk bertumpuh tangan kiri. Fingerboard adalah tempat jari-jari menekan nada dengan ketinggian (pitch) tertentu. Upper boat adalah bagian atas badan biola Waist (C-bouts) adalah pinggang biola/lengkungan biola berbentuk C. F-Holes adalah lubang suara. Bridge adalah kayu tipis yang gunanya untuk menopang senar. Fine tuners adalah alat yang terbuat dari besi untuk pengatur tinggi-rendahnya. nada, fungsinya hampir sama dengan peg-box. Taill piece adalah bagian bawah biola yang digunakan untuk mengikatkan ujung senar biola yang disambungkan ke bagian peg-box lainnya, juga digunakan sebagai tempat untuk meletakkan fine tuner (stemer). Chinrest adalah tempat untuk meletakkan tulang rahang disekitar dagu ketika memainkan biola.

\section{Mengenal Senar Biola (Open string)}

Wilayah suara biola yang paling rendah adalah nada g, secara berurutan dalam posisi setelah ditala atau di stem nada $g$ disebut senar keempat disebelah $g$ adalah nada d disebut senar ketiga, disebelah nada $\mathrm{d}$ adalah nada a disebut senar kedua dan disebelah nada a adalah nada e disebut senar pertama. Senar biola dalam posisi open string diberi simbol dengan angka 0 seperti terlihat dalam garis paranada berikut ini:

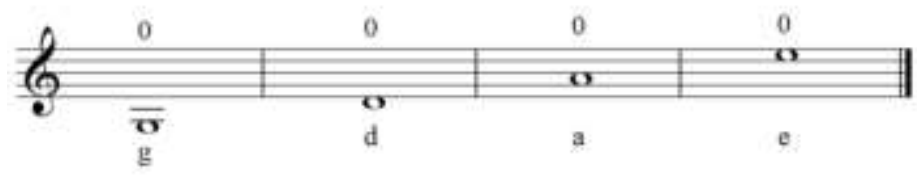

\section{Mengenal Penggesek Biola (Bow)}

Penggesek biola memiliki bagian-bagian sebagai berikut: Screw, Frog, Pad, stick dan hair. Screw berbentuk seperti mur, fungsinya untuk mengatur keseimbangan hair tujuannya bila diputar kekanan digunakan untuk mengencangkan hair biola, bila diputar kekiri untuk melonggarkan hair setelah bermain biola. Frog adalah tempat hair dijepit. Pad adalah gulungan hitam dan putih. Yang hitam dari bahankaret seperti yang putih seperti daribahan tembaga membantu kita menggenggam bow lebih mudah. Stick adalah batang bow dan hair adalah berupa rambut yang terbuat dari bahan sintetis yang gunanya untuk menggesek biola dan berfungsi untuk menghasilkan bunyi nada. 


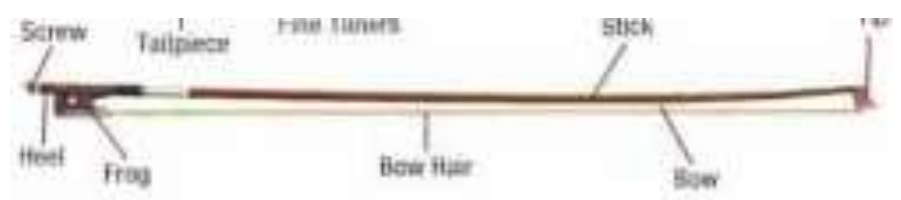

Gambar 2. Penggesek Biola

\section{Teknik Dasar Memainkan biola}

Pembelajaran tentang teknik dasar memainkan biola dimulai dari mengenal dan memahami posisi/sikap tubuh atau kondisi fisik pembelajar yang harus disiapkan. Kondisi fisik yang sehat dan bugar sangat penting agar tahap demi tahapan latihan yang dilakukan dapat dengan mudah diikuti pembelajar. Sikap dan postur tubuh, cara menempatkan biola pada bagian dagu, cara menggunakan penggesek ketika membaca dan memainkan latihan-latihan musikal berupa partitur sebagai bentuk rangkaian proses dalam pembelajaran awal yang harus diikuti dengan sungguhsungguh.

\section{Postur Badan dalam memainkan Biola}

Memainkan biola dimulai dengan memperhatikan sikap tubuh atau cara berdiri sebelum biola ditempatkan pada posisi yang tepat diatas bahu sebelah kiri. Teknik dasar bermain biola diawali dengan cara berdiri. Berdiri hendaknya secara wajar tubuh menghadap ke depan. Posisi badan yang tepat ketika berdiri adalah pelajaran awal yang harus diingat dengan baik, tidak boleh membungkuk atau menengadah, dan pandangan lurus kedepan.

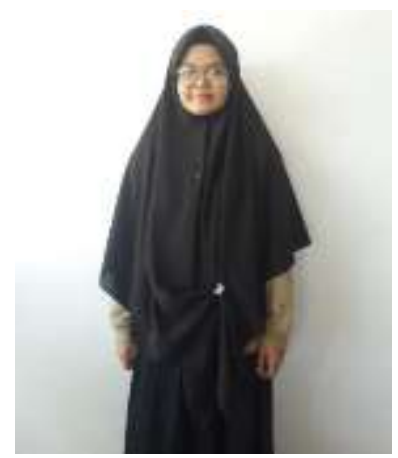

\section{Gambar 3 . Menyiapkan posisi tubuh}

Selanjutnya langkah kedua yang harus ditaati adalah pada saat memegang dan meletakkan biola pada dagu. Menurut Raqmadita Nawang dalam Eka Saputra dkk (2017:5) bahwa posisi memegang biola adalah teknik memegang dan menempatkan biola menggunakan tangan kiri dan meletakkannya pada bahu sebelah kiri. Cara memegang biola dengan baik dan benar merupakan teknik dasar yang harus bisadilakukan oleh pelajar. Teknik ini fokus pada bahu, siku, pergelangan tangan, jari, harus rileks semua. Posisi biola ditempatkan pada bahu sebelah kiri dengan kemiringan biola 45 derajat lurus kedepan dan tulang rahang atau dagu menjepit atau menahan chinrest. Pandangan lurus ke depan sejajar dengan scroll. 


\section{Gambar 4. Meletakkan biola dibawah dagu sebelah kiri}

\section{Menggunakan Penggesek (Bowing)}

Setelah proses belajar cara meletakkan biola pada dagu sebelah kiri, pelajaran dilanjutkan adalah cara memegang bow. Melakukan teknik ini dibutuhkan waktu yang cukup untuk melatihnya. Namun yang terpenting harus dilakukan dengan perasaan rileks dan menyenangkan agar mod latihan terjaga dengan baik. Saat memegang bow posisi bahu tidak boleh naik, pergelangan tangan lurus sesuai siku.

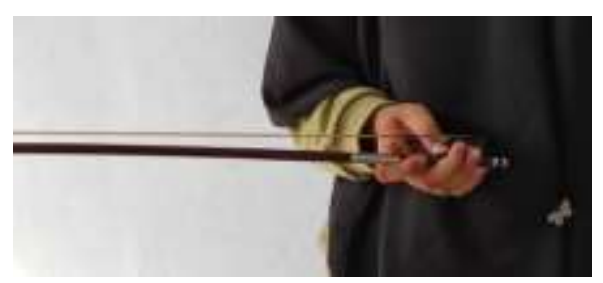

\section{Gambar 5. Cara menempatkan ibu jari dan 4 jari lainnya Memegang Penggesek Biola}

Kekuatan keseimbangan menahan bow terletak pada kekuatan pergelangan tangan dan jari. Posisi ibu jari diletakkan dibawah pangkal hair sementara 4 jari lain menahannya. Posisi telunjuk mengontrol kekuatan bunyi bila digesek harus kuat dan lembut bunyinya disamping itu juga berguna untuk mengontrol gerakan bow agar tetap stabil gesekannya. Posisi tangan kanan membentuk sudut 90 derajat dan tangan kanan tidak boleh merapat ke bagian tubuh untuk menjaga agar leluasa menggerakan tangan kanan naik dan turun ketika menggesek biola.

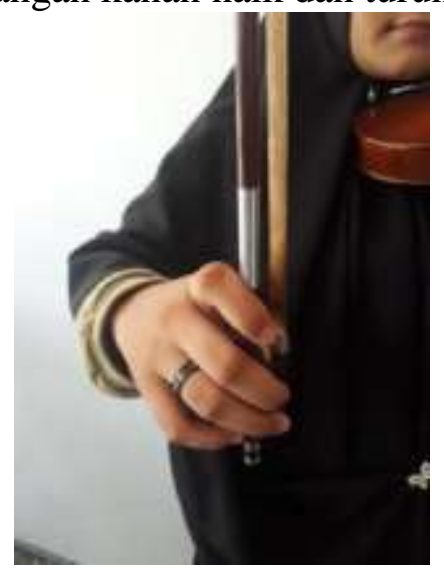

Gambar 6. Cara menempatkan ibu jari dan 4 jari lainnya 
Grenek: Jurnal Seni Musik Vol. 10 No. 1 (Juni 2021) Page: 60-70

Prodi Pendidikan Musik FBS Unimed

p- ISSN 2301-5349

e- ISSN 2579-8200

\section{Menggesek Senar Lepas}

Menggesek senar lepas artinya menggesek senar tanpa menekan senar biola. Biasa juga disebut dengan senar dalam posisi penjarian 0. Beberapa buku panduan belajar biola menggunakan cara yang berbeda dalam memulai menggesek senar lepas. Metode Crikboom memulainya dengan menggesek senar kedua atau senar A begitu juga dengan metode Suzuki I yang memulai menggesek senar A yang dipadu dengan senar E memainkan lagu Twinkle twinkle. Metode Berriot memulai menggesek menggunakan senar ke empat atau senar G. Berikut ini bentuk latihan-latihan yang telah dirangkum dari berbagai sumber berjumlah 13 contoh $\mathrm{A}, \mathrm{B}, \mathrm{C}$, D, E, F, G, H, I, J, K, L dan M seperti yang tampak dalam partitur.

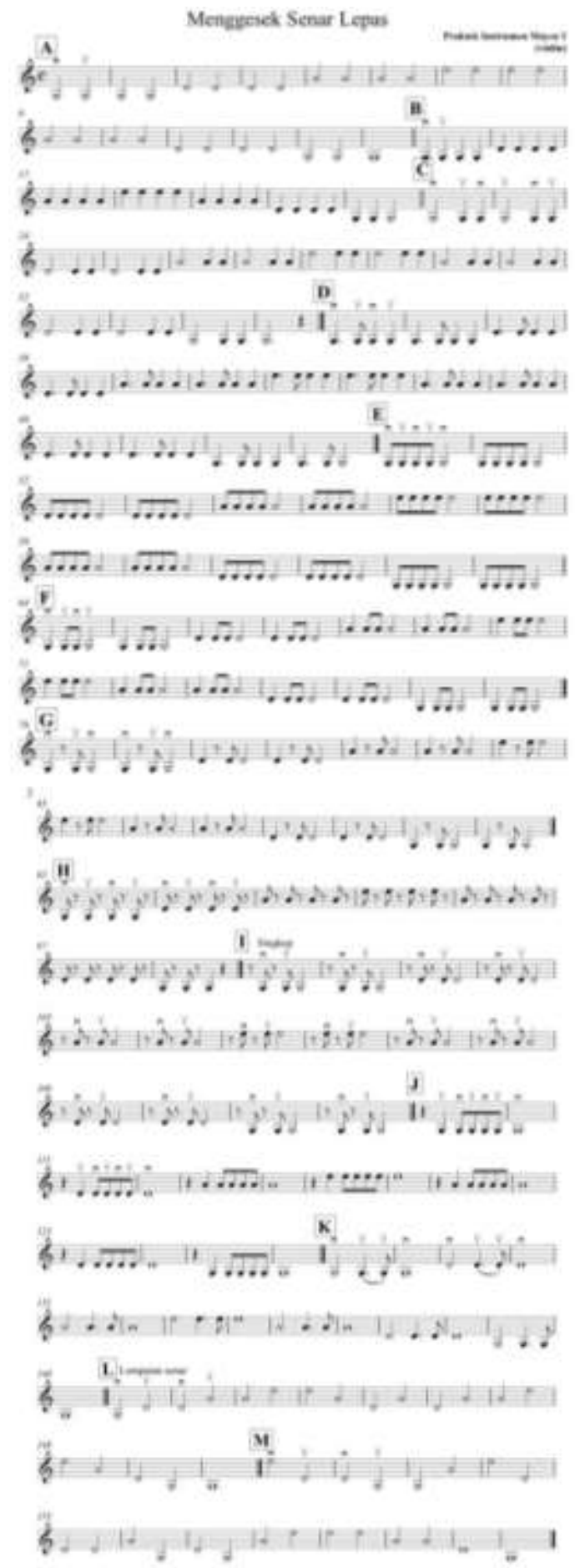


Latihan menggesek senar lepas dilakukan menggunakan nilai not setengah halfnote dimulai dari senar G dilanjutkan ke senar D seterusnya ke senar A dan E. Kemudian kembali ke senar A senar D dan G. Latihan ini dilakukan dengan mengulangnya sampai tiga kali atau lebih sampai mengenal karakter masing-masing senar dalam posisi open string (senar lepas) mendapatkan bunyi benar. Latihan ini terlebih dahulu dilakukan menggunakan tempo lambat adagio kemudian dilanjutkan menambah tempo lebih cepat lagi sesuai rasa masing-masing pelajar. Latihan-latihan ini merupakan awal pengenalan pada setiap senar, oleh karenanya pelajar harus merasakan bunyi dan gerakan penggesek yang harus konsisten membuat gerakan tetap lurus bila berpindah dari down bow ke up bow. Pergantian senar akan merubah kemiringan arah penggesek untuk itu harus dirasakan setiap perpindahan senar agar tidak menggesek senar yang lain.

\section{Menggunakan penjarian $0,1,2,3$ dan 4}

Menggunakan penjarian yang tepat dengan teknik yang benar adalah kunci keberhasilan dalam menghasilkan bunyi nada yang tepat. Pembentukan frame (kerangka) jari menjadi penting untuk memastikan nada di tekan dengan benar sesuai notasi yang diharapakan Menempatkan penjarian membutuhkan energi, konsentrasi dan kepekaan perasaan (feeling). Kepekaan terhadap nada agar tidak fals dapat dilakukan dengan bantuan solfegio atau ikut menyuarakan nada dalam hati pada saat nada-nada itu dimainkan. Melatih bagian ini dimulai dengan meletakkan ibu jari (thumb) yang tepat. Posisi senar lepas (open string) diberi simbol nomor 0. Jari-jari tangan kiri diberi lambang nomor 1 sampai 4, nomor 1 untuk jari telunjuk, nomor 2 untuk jari tengah, nomor 3 untuk jari manis dan nomor 4 untuk jari kelingking (Kustap : 2008). Untuk kemudahan memindahkan jari demi jari dibantu dengan kekuatan dagu dan pundak menahan biola, sehingga jari 1, 2, 3 dan 4 bisa lebih leluasa bergerak di sepanjang leher biola. Latihan terstruktur yang harus diikuti dengan sungguh-sungguh adalah sebagai latihan berikut ini :

a. Latihan 1

Latihan 1 ini dimaksud untuk mencari jalan yang tepat dimana posisi jari sesuai dengan nada yang dituju. Latihan 1 memberi cara agar jari-jari berada dalam kontrol nada yang sesuai. Pada saat menempatkan jari 1 posisinya tepat dan untuk bergerak ke jari 2 jari 1 tetap dalam posisi menekan atau tidak dilepas atau diangkat. Begitu juga dengan ketika menekan jari 3 dan 4 posisi jari 1 tetap bertahan atau tidak diangkat.

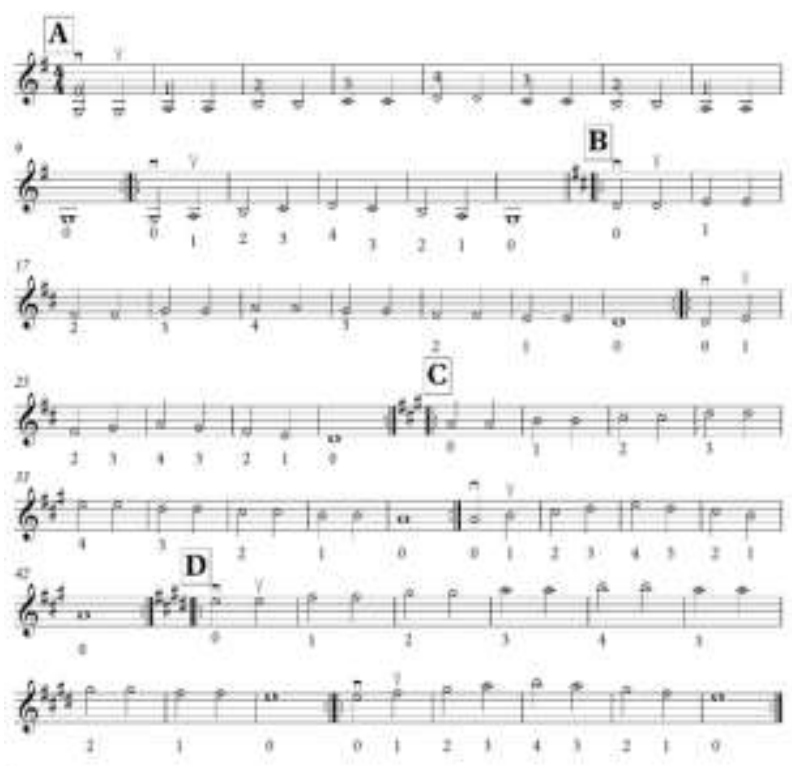


Grenek: Jurnal Seni Musik Vol. 10 No. 1 (Juni 2021) Page: 60-70

Prodi Pendidikan Musik FBS Unimed

p- ISSN 2301-5349

e- ISSN 2579-8200

\section{a. Latihan 2}

Setelah mengikuti latihan 1 selanjutnya dikembangkan penguatan penjarian dengan penggunaan gabungan nilai not half note dan quater not atau not seperempat dengan latihan berikut yang berlaku untuk semua senar.

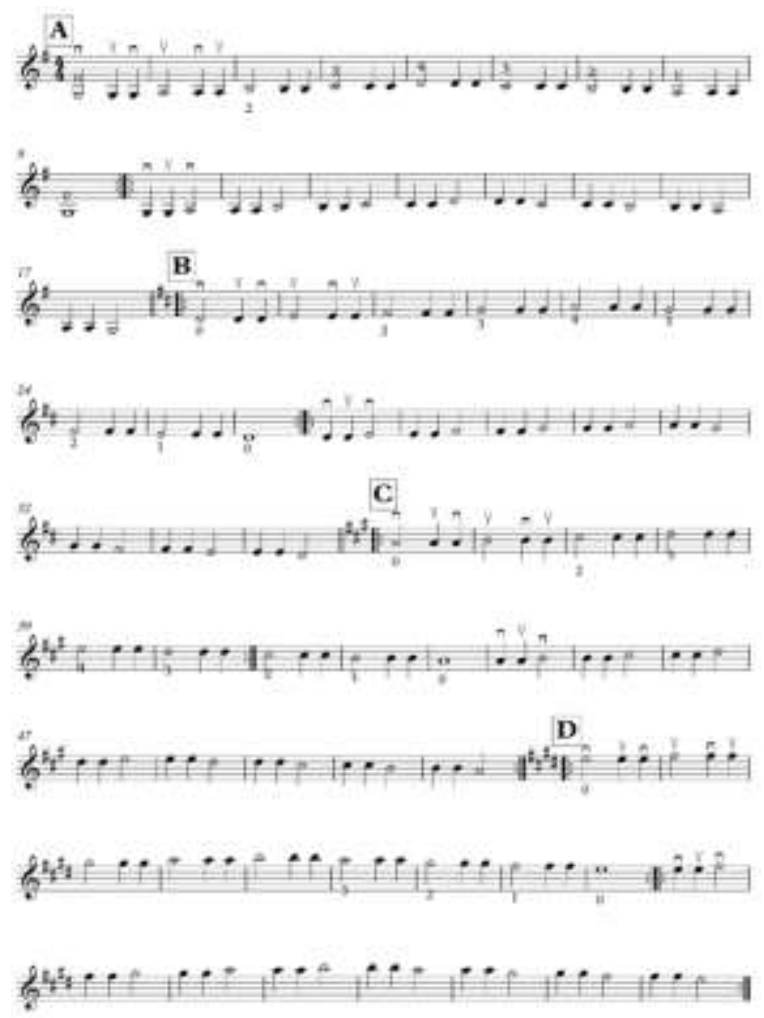

\section{Menggunakan penggesek Whole Bow (W.B)}

W.B artinya teknik menggesek menggunakan seluruh bagian penggesek dengan hitungan yang telah ditentukan. Tujuan penggunaan W.B ini untuk melatih gerakan penggesek agar tetap konstan atau stabil dimulai dari pangkal penggesek (down bow) menuju ujung penggesek (up bow). Untuk mengontrol penggesek agar tetap lurus maka dianjurkan untuk menggunakan cermin. Tujuan penggunaan cermin untuk melihat gerakan tangan menjaga posisi penggesek dalam posisi yang tetap lurus. Manfaat yang dirasakan dengan latihan ini adalah terbentuknya kekuatan tangan kanan yang kokoh dalam menggesek terutama bagian telunjuk yang harus mengontrol agar gerakan bow tetap lurus. Latihan yang dapat dilakukan untuk menerapkan teknik W.B diantaranya dalam memainkan tangga nada dan arpeggio G Mayor 2 oktaf dan lagu twinkletwinkle :

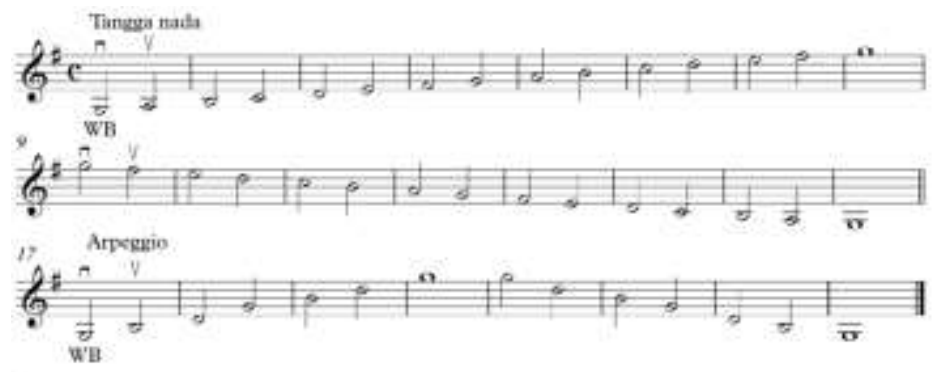




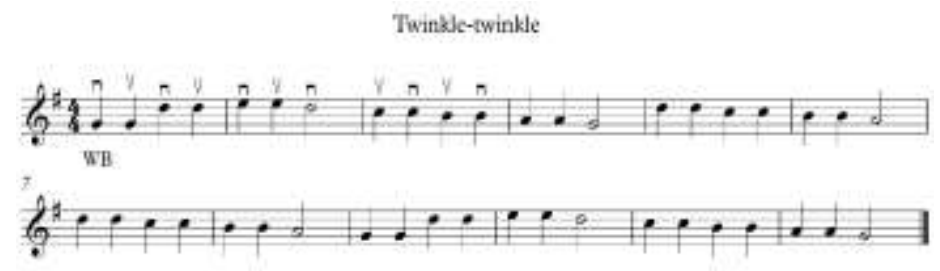

\section{Menggunakan teknik gesekan legato}

Legato ( $\frown$ ) artinya teknik menggesek menggunakan satu gesekan dengan beberapa not. Tujuan penggunaan gesekan legato ini untuk menyambung atau melatih gerakan bow agar tetap konstan atau stabil yang dimulai dari pangkal penggesek (down bow) menuju ujung penggesek (up bow). Latihan-latihan yang dapat dilakukan untuk menerapkan teknik gesekan legato dapat dilakukan dengan memainkan tangganada dan arpeggio G Mayor 2 oktaf dan lagu Long-long Ago berikut ini:
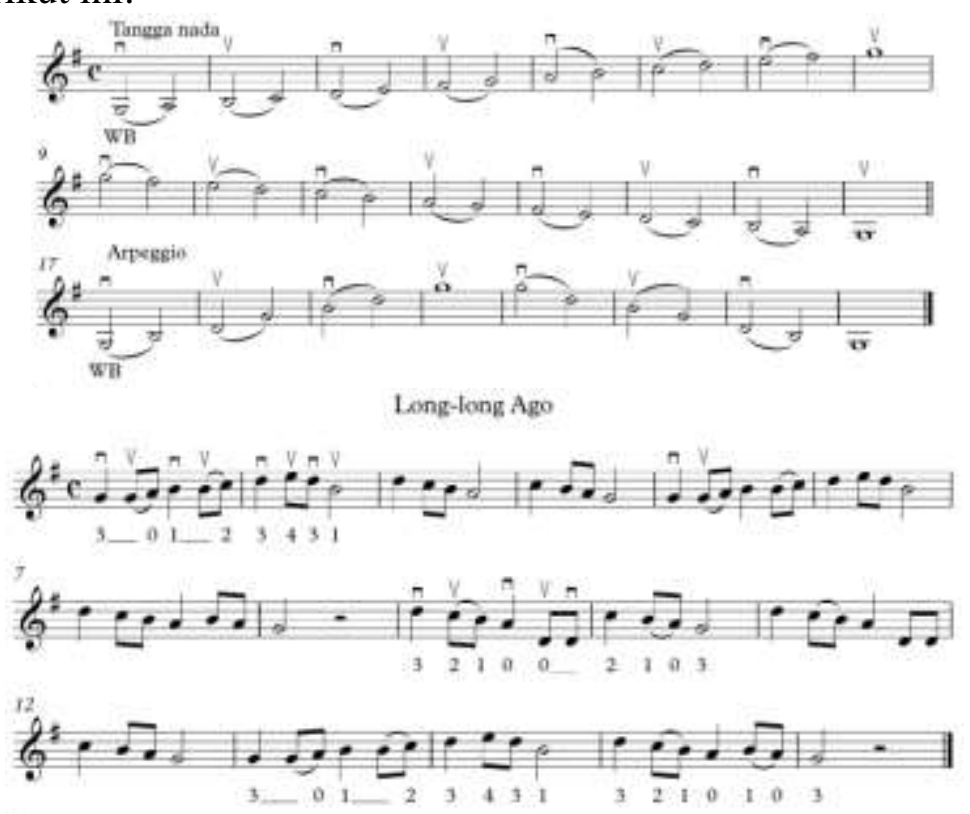

\section{Menggunakan teknik gesekan staccato}

Staccato (.) artinya teknik menggesek dengan cara putus-putus. Simbol untuk teknik ini adalah nada diberi tanda titik dibawah atau diatas not yang dimainkan. Perubahan bunyi terjadi pada saat memainkan nada dengan teknik staccato, nada berubah bunyi dan nilainya menjadi setengah dari not yang tertulis atau dibunyikan lebih pendek. Manfaat yang dirasakan dengan latihan ini adalah terbentuknya kekuatan tangan kanan terutama jari telunjuk yang mengontrol bunyi agar konsisten. Latihan-latihan dapat dilakukan dalam memainkan tangganada dan arpeggio G Mayor 2 oktaf dan lagu Allegro dalam nada dasar G Mayor berikut :

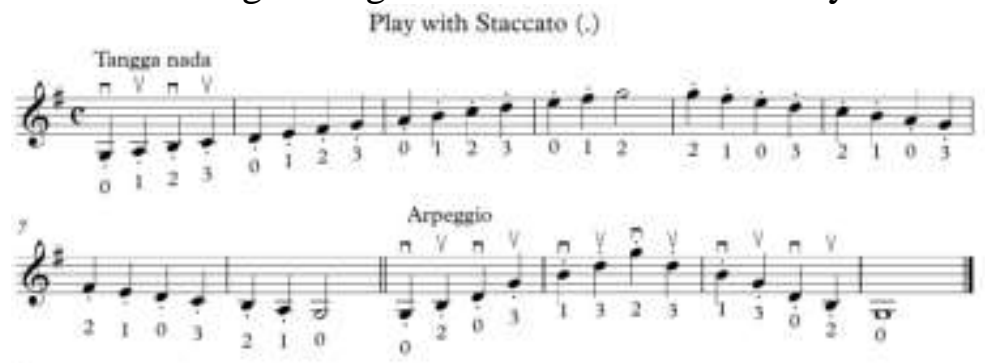




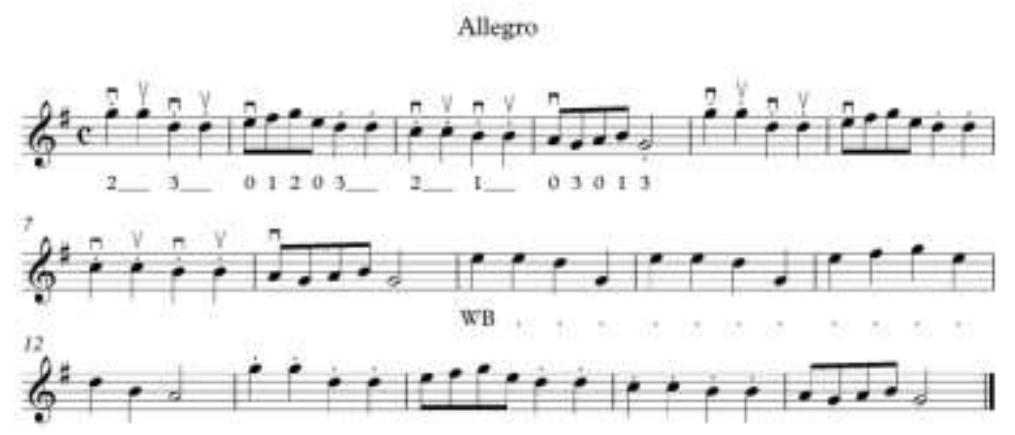

\section{SIMPULAN}

Penelitian ini adalah untuk menjelaskan tahap demi tahap latihan dalam pembelajaran praktek instrumen mayor I prodi pendidikan musik jurusan Sendratasik melatih tangan kanan supaya gerakan penggeseknya tetap dalam memainkan tangganada dan arpeggio. lurus dalam menggesek biola, Melatih kualitas bunyi gesekan secara konsisten, Melatih kesabaran dan konsentrasi dalam menggesek biola. Mahasiswa bisa menerapkan teknik bermain biola menggunakan bowing dalam memainkan Long senar, menggunakan penjarian 123 dan 4 menggunakan jenis gesekan dengan teknik legato dan staccato. sebagai materi ajar praktek instrumen mayor 1 untuk dapat mengekspresikan repetoar lagu secara maksimal.

Berdasarkan hasil penelitian dapat disimpulkan bahwa pemahaman terhadap postur tubuh yang tepat dan penggunaan teknik bowing whole bow legato dan staccato. Sikap dan postur tubuh, cara menempatkan biola pada bagian dagu, cara menggunakan penggesek ketika membaca dan memainkan latihan-latihan musikal berupa partitur sebagai bentuk rangkaian proses dalam pembelajaran awal yang harus diikuti dengan sungguh-sungguh.

\section{Daftar Pustaka}

Banoe, P. (2003). Kamus Musik. Yogyakarta. Kanisius. Nawang. (2009). Cara Mudah Bermain Biola Untuk Pemula. Yogyakarta : Ekspresi

Paul Herfurth (2018). A Tune A Day. Bostom Music Company.

Saryono. (2013). Metode Penelitian Kualitatif. Bandung. Alfabeta.

Saputra dkk. (2018). Teknik Bermain Biola di Warna Harmoni Orchestra (WHO) Pekanbaru Provinsi Riau. Jurnal KOBA Volume 5, No 1.

Slameto. (2013). Belajar dan Faktor-faktor yang mempengaruhi. Jakarta: Cetakan keenam, PT Rineka Cipta.

Sudjana, Nana (2013). Dasar-dasar proses belajar mengajar. Bandung: Sinar Baru algesindo.

Sudjana, Nana (2013). Penilaian Hasil Proses Belajar Mengajar. PT. Remaja Rosdakarya.

Sugiyono. (2011). Metode Penelitian Pendidikan: (Pendekatan Kuantatif, Kualitatif, R\&D). Bandung: Alfabeta. 